\title{
Specific PKC isoforms regulate LPS-stimulated iNOS induction in murine microglial cells
}

Jie Wen ${ }^{1}$, Rachel Ribeiro ${ }^{2}$ and Yumin Zhang ${ }^{1,2^{*}}$

\begin{abstract}
Background: Excessive production of nitric oxide (NO) by inducible nitric oxide synthase (iNOS) in reactive microglia is a major contributor to initiation/exacerbation of inflammatory and degenerative neurological diseases. Previous studies have indicated that activation of protein kinase C (PKC) can lead to iNOS induction. Because of the existence of various PKC isoforms and the ambiguous specificity of PKC inhibitors, it is unclear whether all PKC isoforms or a specific subset are involved in the expression of iNOS by reactive microglia. In this study, we employed molecular approaches to characterize the role of each specific PKC isoform in the regulation of iNOS expression in murine microglia.
\end{abstract}

Methods: Induction of iNOS in response to bacterial endotoxin lipopolysaccharide (LPS) was measured in BV-2 murine microglia treated with class-specific PKC inhibitors, or transfected with siRNA to silence specific PKC isoforms. iNOS expression and MAPK phosphorylation were evaluated by western blot. The role of NF- $\kappa \mathrm{B}$ in activated microglia was examined by determining NF- $\kappa$ B transcriptional response element- (TRE-) driven, promotermediated luciferase activity.

Results: Murine microglia expressed high levels of nPKCS, and expressed relatively low levels of cPKCs and aPKCs. All PKC inhibitors attenuated induction of iNOS in LPS-activated microglia. Knockdown of PKC $\delta$ and PKC $\beta$ attenuated ERK1/2 and p38 phosphorylation, respectively, and blocked NF- $\kappa$ B activation that leads to the expression of iNOS in reactive microglia.

Conclusions: Our results identify PKC $\delta$ and $\beta$ as the major PKC isoforms regulating iNOS expression in reactive microglia. The signaling pathways mediated by PKC involve phosphorylation of distinct MAPKs and activation of NF- $\kappa$ B. These results may help in the design of novel and selective PKC inhibitors for the treatment of many inflammatory and neurological diseases in which production of NO plays a pathogenic role.

\section{Background}

Microglia are distributed throughout the central nervous system (CNS) as resting immunocompetent cells derived from a monocyte/macrophage lineage [1,2]. When activated, microglia protect neurons by clearing toxic cell debris and pathogens, and acting as antigen presenting cells to induce innate immune responses [3]. However, excessive activation of microglia can also release a variety of toxic factors including reactive oxygen species (ROS), reactive nitrogen species (RNS) and proinflammatory cytokines, which cause toxicity to the

\footnotetext{
* Correspondence: yzhang@usuhs.mil

'Department of Anatomy, Physiology and Genetics, Uniformed Services University of the Health Sciences, 4301 Jones Bridge Road, Bethesda, MD 20814, USA

Full list of author information is available at the end of the article
}

neighboring cells such as neurons and oligodendrocytes (OLs). A pathogenic role for nitric oxide has been implicated in many inflammatory and neurodegenerative diseases, including multiple sclerosis, stroke and traumatic brain injury [4-7]. Understanding the potential mechanisms that turn beneficial inflammatory responses into detrimental action is crucial for identifying therapeutic targets to intervene in self-sustained inflammatory cycles.

Nitric oxide $(\mathrm{NO})$, generated from $\mathrm{L}$-arginine by nitric oxide synthase (NOS), has been shown to be both a signaling and an effector molecule in diverse biological systems [8-10]. Among the three isoforms of NOS identified, neuronal NOS (nNOS) and endothelial NOS (eNOS) are $\mathrm{Ca}^{2+}$ dependent [8-13], and inducible NOS (iNOS) functions in a $\mathrm{Ca}^{2+}$-independent manner $[10,13]$. 
Induction of iNOS occurs primarily in astrocytes and microglia in response to endotoxin or to proinflammatory cytokines, such as TNF $\alpha$, IL-1 $\beta$ or IFN $\gamma$ [14]. Using pharmacological inhibitors and molecular approaches, studies have shown that NO can react with superoxide to form peroxynitrite in reactive microglia causing toxicity to neurons and OLs $[15,16]$. Although it is known that activation of various transcription factors - such as STAT, NF- $\kappa$ B , AP-1, and C/ERP - can contribute to the production of NO [17-20], the signaling pathways regulating expression of iNOS and production of $\mathrm{NO}$ in the CNS are still not well understood.

Protein kinase $\mathrm{C}(\mathrm{PKC})$ is a family of serine/threonine kinases that regulate cellular responses elicited by hormones, neurotransmitters and growth factors [21]. Based on differences in sequence homology between these isozymes and their requirements for cofactors, the PKC family is divided into conventional PKCs (cPKC: $\alpha$, $\beta$ and $\gamma$ ), novel PKCs (nPKC: $\delta, \varepsilon, \eta$ and $\theta$ ) and atypical PKCs (aPKCs: $\zeta$ and $\lambda / \mathrm{l}$ ) [22,23]. PKC isoforms are widely expressed in many cell types, including microglia/macrophages [24], and studies have shown that PKC activation is an important mediator of microglial activation $[25,26]$. PKC inhibitors reduce NO synthesis from IFN- $\gamma$-treated microglia and PKC $\delta$ is able to regulate NF- $\kappa \mathrm{B}$ activation and iNOS expression in mouse peritoneal macrophages [27]. Because of the existence of various $\mathrm{PKC}$ isoforms and the ambiguity of action of PKC inhibitors, the role of specific PKC isoforms involved in the inflammatory response in microglia has not been elucidated. In this study we used murine microglial cell line BV-2 cells to examine the signaling pathways by which PKC activation leads to iNOS induction in LPS-activated microglia. Our results indicate that all PKC isoforms are expressed in BV-2 cells with a particularly high expression of $\mathrm{nPKC}$. Although several PKC isoforms can mediate lipopolysaccharide- (LPS-) stimulated increases in iNOS expression, PKC $\delta$ and $\beta$ are likely the major PKC isoforms responsible for PKC function in reactive microglia. Furthermore, we found that distinct mitogen activated protein kinases (MAPKs) are activated in response to specific PKC isoforms and result in iNOS induction. Elucidation of the signaling pathways mediated by the different $\mathrm{PKC}$ isoforms in iNOS expression in reactive microglia will facilitate the development of isoform-specific PKC inhibitors with the potential to avoid the side effects of pan-PKC inhibitors.

\section{Methods}

\section{Materials}

Fetal bovine serum (FBS) and Dulbecco's modified Eagle's medium (DMEM) were purchased from Invitrogen (Carlsbad, CA). The BV-2 cell line was a generous gift from Dr. Feng-Qiao Li, Cognosci Inc., NC. Bacterial
LPS (Escherichia Coli O111:B4) was obtained from Sigma (St. Louis, MO). 2',7'-dichlorohydrofluorescein diacetate (DCF) was purchased from Molecular Probes, Inc. (Eugene, OR). Antibodies against phosphorylated and total p38, extracellular signal regulated kinase $1 / 2$ (ERK1/2) and c-Jun N-terminal kinase (JNK) were purchased from Cell Signaling Technology (Danvers, MA). Anti-iNOS antibody was purchased from BD biosciences (San Diego, CA). PKC siRNAs were purchased from Santa Cruz Biotechnology (Santa Cruz, CA). Bisindolylmaleimide-1 (Bis-1), Rottlerin, GO6976, SB203580, SP600125 and U0126 were purchased from Calbiochem (Gibbstown, NJ). Transfection reagents were from Roche (Basel, Switzerland) and Luciferase assay kit was from Promega (Madison, WI).

\section{Cell culture}

Immortalized murine microglial cells (BV-2) were cultured in $100 \mathrm{~mm}$ dishes in DMEM containing 5\% FBS, $1 \%$ penicillin/streptomycin at $37^{\circ} \mathrm{C}$ in an incubator with a humidified atmosphere of $95 \%$ air and $5 \% \mathrm{CO}_{2}$.

\section{Quantitative real-time PCR and reverse transcriptase PCR analysis}

Total RNA was isolated from cultured BV-2 cells using RNeasy Mini Kit (Qiagen, Valencia, CA) and cDNA synthesis from total RNA was performed using a ReveriAid First Strand cDNA synthesis kit (Fermentas, Glen Burnie, MD) using $1 \mu \mathrm{g}$ total RNA and $1 \mu \mathrm{l}$ oligo $(\mathrm{dT})_{18}$ following the manufacturer's instructions. Quantitative real time PCR was conducted with $\mathrm{CDNA}$ as a template in a 7500 Real time PCR System using SYBR Green PCR master mix (Applied Biosystems, Foster city, CA). The primers for target genes are shown in table 1. All samples were run in triplicate for PCR amplification. Relative values for mRNA expression were determined from their optimized threshold cycle $\left(\mathrm{C}_{\mathrm{T}}\right)$ normalized against the $C_{T}$ value of an internal control gene, GAPDH, by using the comparative $C_{\mathrm{T}}$ method (User Bulletin 7500, Applied Biosystems). To test for downregulation of PKC isoforms by specific PKC siRNA, total mRNA isolated from PKC siRNA or RISC-free siRNAtransfected BV-2 cells was used to synthesize cDNA as described above. One microliter of each cDNA, synthesized in a reverse transcriptase reaction, was used for PCR amplification in the presence of $1 \mathrm{U}$ Taq DNA polymerase in Tag buffer, $0.2 \mathrm{mM}$ each of dNTPs, and $1 \mu \mathrm{M}$ of each primer. Each sample was amplified for different cycles according to the expression level of each gene in the cells. PKC $\alpha, \beta$ and $\theta$ were amplified for 32 cycles, PKC $\varepsilon$ and $\eta$ were amplified for 28 cycles, and PKC $\delta$ was amplified for 26 cycles. The PCR amplification reaction used a three-step program $\left(30 \mathrm{sec}\right.$ at $95^{\circ} \mathrm{C}$, $30 \mathrm{sec}$ at $60^{\circ} \mathrm{C}$, and $45 \mathrm{sec}$ at $72^{\circ} \mathrm{C}$ ). The PCR product 
Table 1 Primer sequences of mouse PKC isoforms.

\begin{tabular}{|c|c|c|}
\hline PKC isoform & Forward & Reverse \\
\hline $\bar{\alpha}$ & $5^{\prime}-c c c a t t c c a g a$ a g g a g a t g a-3' & $5^{\prime}$-t tcctgtcagcaagcatcac-3' \\
\hline$\beta$ & $5^{\prime}$-t c c c tg a t c c c a a a a g t g a g-3' & $5^{\prime}-\mathrm{a}$ a c t t g a a c c a g c c a t c c a c-3' \\
\hline$\delta$ & $5^{\prime}-c$ a g a c c a aggaccacctg t t-3' & $5^{\prime}-g c$ a t a a a c gtagc c c g g t a- $3^{\prime}$ \\
\hline$\gamma$ & $5^{\prime}-a$ c c a g g g c a t c a tct a c a g g-3' & $5^{\prime}-\mathrm{cttcctcatcttccccatca-3^{ \prime }}$ \\
\hline$\varepsilon$ & $5^{\prime}-g$ a g g a ctg g a t tg a c ctg g a-3' & $5^{\prime}-a$ t c t c t g c a g t g g g a g c a g t- $3^{\prime}$ \\
\hline$\eta$ & 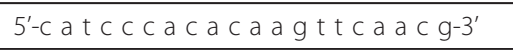 & $5^{\prime}-a$ t a t t t c c g g g t t g ga g a c c-3' \\
\hline $\bar{\lambda}$ & $5^{\prime}-t$ a t g g c t tca gcgttgact g-3' & $5^{\prime}-c c t t t g g g t c c t t g t t g a g a-3^{\prime}$ \\
\hline$\theta$ & $5^{\prime}-a \operatorname{tg} g$ a c a a c c c cttct a c c c-3' & $5^{\prime}-g c g g a t g t c t c c t c t c a c t c-3^{\prime}$ \\
\hline$\zeta$ & 5'-a a g tg g g tg g a c a g t g a a g g-3' & $5^{\prime}-\mathrm{c}$ a g c t t c ctccatct tct g g-3' \\
\hline
\end{tabular}

was run on $1.5 \%$ agarose gels and visualized under UV light.

\section{PKC activity assay}

The activity of PKC in BV-2 cells following LPS treatment was measured using a PKC activity assay kit from Assay Designs, Inc (Ann Arbor, MI). In brief, BV-2 cells cultured in 24-well plates were treated with $1 \mu \mathrm{g} / \mathrm{ml}$ LPS for $30 \mathrm{~min}$ and then washed with cold PBS twice and lysed with protein lysis buffer. Whole cell lysates were adjusted to equal protein concentrations with lysis buffer and the same volume of each sample was added to ELISA plates pre-coated with crebtide, a substrate that can be readily phosphorylated by PKC. ATP was added to each well to initiate reaction at $30^{\circ} \mathrm{C}$ for 90 min. After emptying the contents of each well, phosphospecific substrate antibody was added and incubated for $1 \mathrm{hr}$. The phosphorylated crebtide was quantitated following the manufacturer's instructions.

\section{Western blot analysis}

Whole cell lysates from cultured BV-2 cells were obtained by using ice-cold protein lysis buffer (containing $1 \times$ TBS, $1 \%$ Nonidet P-40, $0.5 \%$ sodium deoxycholate, $0.1 \%$ SDS, $0.004 \%$ sodium azide) with freshly added protease inhibitor cocktail and glycerophosphate and sodium orthovanadate. The lysates were subjected to centrifugation at $10,000 \mathrm{~g}$ for $10 \mathrm{~min}$ at $4^{\circ} \mathrm{C} .5 \mu \mathrm{g}$ of whole cell lysates were boiled for $5 \mathrm{~min}$, and separated on Novex 4-12\% Bis-Tris gel. Proteins were transferred to PVDF membrane using a Bio-Rad mini-trans-blot cell. Transferred blots were blocked by incubating the membranes with 5\% BSA for $1 \mathrm{hr}$ at room temperature to reduce non-specific binding. Blocked membranes were incubated with primary antibodies overnight. These antibodies include rabbit polyclonal anti-phosphorylated and total ERK1/2, JNK and p38 (all with dilution of 1:1000), mouse anti-iNOS (1:1000), mouse anti-PKC $\alpha, \beta, \delta, \varepsilon$ and $\gamma$ (BD Transduction Laboratories, $1: 1000)$ and rabbit anti-PKC $\eta, \lambda, \theta$ and $\zeta$ polyclonal antibodies (Santa Cruz, all with 1:500 dilution). After washing with $1 \times$ TBS-T (Tris-buffered saline containing $1 \%$ Tween 20 ), the membranes were incubated with goat anti-rabbit or goat anti-mouse horseradish peroxidase (HRP) conjugated secondary antibody (1:2000) for $1 \mathrm{hr}$ at room temperature. Finally, the membranes were incubated in Chemiluminescence western blot detection reagents from Pierce (Rockford, IL) for $1 \mathrm{~min}$ and protein was visualized with Image Reader LAS-3000 software.

\section{Nitrite measurement}

The level of accumulated nitrite in the medium was determined by the Greiss reaction. Briefly, $50 \mu \mathrm{l}$ of Greiss reagent (3.9 mM N-(1-naphthyl)ethylenediamine/ $58 \mathrm{mM}$ sulfanilamide/5\% phosphoric acid) was added to $50 \mu \mathrm{l}$ of culture supernatant in a 96-well plate. Absorbance was measured at wavelength $550 \mathrm{~nm}$, and nitrite concentration was calculated from a standard curve of sodium nitrite.

\section{siRNA transfection}

In order to specify the role of each PKC isoform in iNOS induction by LPS-activated microglia, doublestranded siRNA oligonucleotides for each PKC isoform (purchased from Santa Cruz) were transfected into BV-2 cells with $\mathrm{X}$-treme transfection reagent $(60 \mathrm{nmol}$ siRNA/well). The day before the transfection, BV-2 cells were split and plated into 24-well plates at a density of $2 \times 10^{5}$ cells/well to assure cells around $80 \%$ confluency at the time of transfection. The transfected cells were continuously incubated at $37^{\circ} \mathrm{C}$ for $48 \mathrm{hr}$ before use for further experiments. siGLO RISC-free siRNA from Dharmacon was used as a negative control and its fluorescence was also used for evaluating transfection efficiency.

\section{Plasmid transfection and luciferase assay}

The reporter gene with NF- $\kappa \mathrm{B}$ promoter was transfected into BV-2 cells. In brief, the cells were trypsinized and 
plated into 96-well plates at a density of $5 \times 10^{4}$ cells/ well. The transfection was performed with FuGene HD transfection reagent. One microgram plasmid containing NF- $\kappa \mathrm{B}$ promoter or GFP was mixed with $0.25 \mu \mathrm{l}$ FuGene HD in a total volume of $5 \mu \mathrm{l}$ of serum-free DMEM for each reaction. At $24 \mathrm{hr}$ after transfection, cells were treated with LPS for $3 \mathrm{hr}$ in the presence of various PKC and MAPK inhibitors. Assessment of luciferase activity in transfected cells was carried out with a luciferase reporter assay system from Promega following the manufacturer's instructions.

\section{Statistical analysis}

Data were analyzed for statistical significance using a two-tailed t test (comparison of two data sets) or with analysis of variance (ANOVA, comparison of multiple data sets). A significant difference was determined as $\mathrm{p}$ $<0.05$. All experiments were performed in triplicate and have been repeated at least three times.

\section{Results}

\section{ALL PKC isoforms are present in microglia and activated} by LPS

It has been reported that inhibitors of PKC can reduce iNOS induction in reactive microglia [28-30]. However, the specific PKC isoforms that are involved are not known. In order to identify the specific PKC isoforms that are required for iNOS production, we first examined which PKC isoforms are expressed in BV-2 by quantitative real-time PCR. The results indicate that while mRNAs encoding all the PKC isoforms are detectable, there are significantly higher levels of $\mathrm{nPKC}(\delta, \eta$, $\varepsilon)$ expression compared to the conventional $(\alpha, \beta, \gamma)$ and the atypical $(\lambda / \mathrm{t})$ isoforms (Figure $1 \mathrm{~A})$. Using isoform-specific antibodies, we found that each of the PKC isoforms is also expressed in BV-2 cells (Figure 1B). In contrast to a report by Kang and colleagues [31], but consistent with results from Sun's group [29], we detected very low amounts of PKC $\alpha$ and $\beta$ and very high levels of PKC $\delta$, suggesting that nPKC isoforms may account for the major PKC activity in reactive microglia. In order to confirm PKC is activated in LPStreated microglia, we measured PKC activity in murine BV-2 cells using ELISA. As shown in Figure 1C, PKC activity is elevated after treatment with LPS for $30 \mathrm{~min}$, and suppressed by several PKC inhibitors, which include the pan-PKC inhibitor, Bis-1, the $\mathrm{nPKC}$-selective inhibitor, rottlerin, and the cPKC-selective inhibitor, GO6976 $[32,33]$. These results demonstrate that both $\mathrm{CPKC}$ and $\mathrm{nPKC}$ might be functionally important in BV-2 cells when activated by LPS.

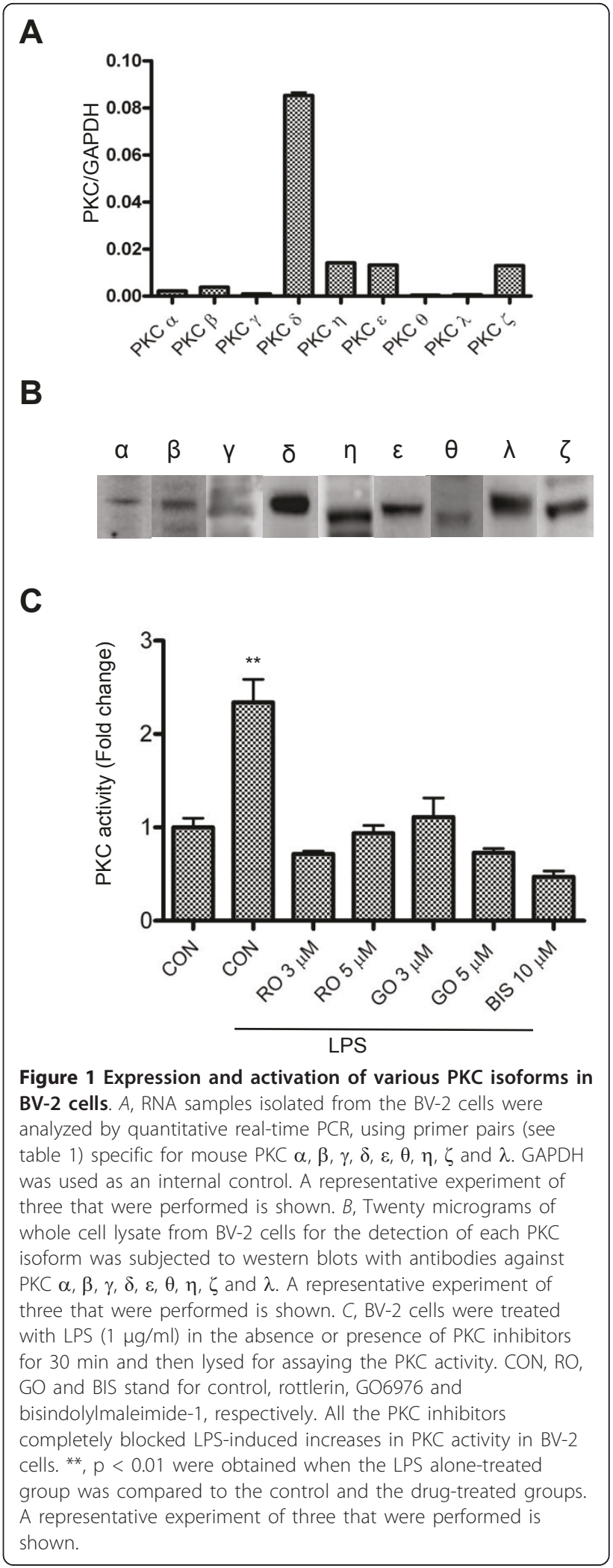




\section{PKC inhibitors attenuate iNOS expression in reactive microglia}

The discovery of relatively isozyme-specific PKC inhibitors has provided important information regarding the function of individual PKC isoforms. It has been reported that rottlerin specifically inhibits $\mathrm{PKC} \delta$ while GO6976 mainly targets conventional PKC, and Bis-1 has inhibitory effects on all PKC isozymes [32,33]. To determine whether iNOS induction is attributable to the activation of PKC, BV-2 cells were treated with LPS in the presence of the aforementioned PKC inhibitors. At $6 \mathrm{hr}$ following LPS treatment, cells were lysed and iNOS production was determined by western blot. All of the PKC inhibitors were able to suppress iNOS expression to different degrees. However, rottlerin seems to have the greatest inhibitory effect (Figure 2A). In comparing these, rottlerin at $5 \mu \mathrm{M}$ near completely (94\%) blocks LPS-induced iNOS production, GO6976 at $5 \mu \mathrm{M}$ causes $60 \%$ inhibition and Bis-1 at $10 \mu \mathrm{M}$ inhibits iNOS production by $89 \%$ (Figure 2B). Consistently, NO production was also significantly attenuated when cells were treated with PKC inhibitors (Figure 2C). These results confirm that PKC activation is an integral component of LPS-induced iNOS expression and suggest that $\mathrm{nPKC}$ isoforms might play a prominent role in iNOS induction in BV-2 cells.

\section{Activation of MAPK occurs downstream PKC, but upstream iNOS induction in reactive microglia}

It is well known that MAPK cascades are involved in cytokine- and LPS-mediated iNOS induction in microglial cells [34]. However, the involvement of specific MAPKs varies in different cell types and in response to different stimuli. At various times after LPS treatment, all three MAPKs in BV-2 cells are transiently phosphorylated. p38 phosphorylation occurs at $5 \mathrm{~min}$, reaches maximum at $30 \mathrm{~min}$, and nearly disappears at 1 hr following LPS treatment. The phosphorylation of JNK and ERK1/2 is present after 15 min of LPS treatment and remains at the same level until $30 \mathrm{~min}$, followed by a dramatic reduction at $1 \mathrm{hr}$ (Figure 3 ).

Using U0126, SB203580 and SP600125, inhibitors of ERK1/2, p38 and JNK, respectively [35], we found that iNOS induction and NO production in reactive microglia were significantly inhibited (Figure 4A-C). There was no change in cell viability at $24 \mathrm{hr}$ following drug treatment (data not shown). To investigate the possible relationship between PKCs and MAPKs, we examined activation of MAPKs in the presence of PKC inhibitors. We found that MAPK phosphorylation at $15 \mathrm{~min}$ following LPS treatment is attenuated by PKC inhibitors, indicating that activation of $\mathrm{PKC}$ occurs upstream of MAPKs. The nPKC selective inhibitor rottlerin attenuates ERK1/2 phosphorylation by $63 \%$, but has no effect

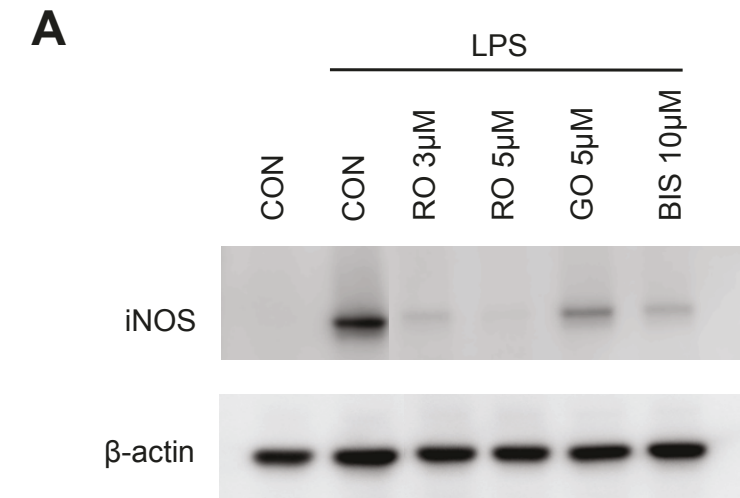

B

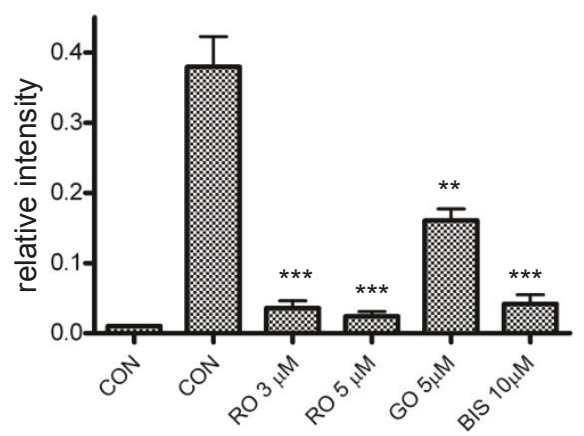

C

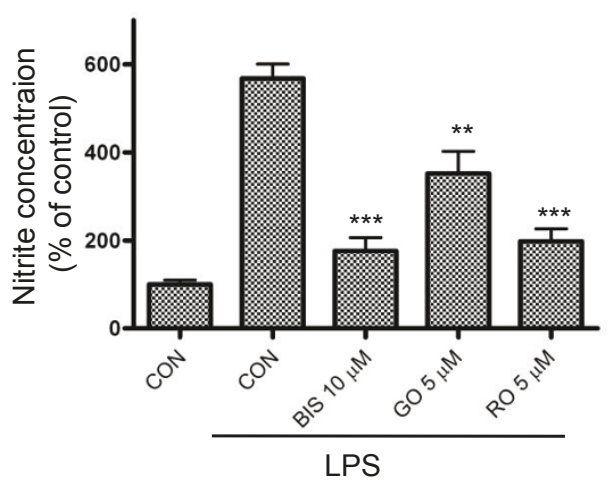

Figure 2 Effects of PKC inhibitors on iNOS expression in BV-2 cells. A, BV-2 cells were treated with LPS $(1 \mu \mathrm{g} / \mathrm{ml})$ for $6 \mathrm{hr}$ in the presence of PKC inhibitors at the indicated concentrations. Aliquots of cell extracts prepared from the above treated cultures were subjected to western blot analysis by using antibodies against iNOS and $\beta$-actin. A representative experiment of four that were performed is shown. $B$, The levels of iNOS expression with various treatment conditions were normalized by $\beta$-actin and quantified using densitometric analysis. The data were pooled from 4 different experiments. ${ }^{* *}, p<0.01$ and ${ }^{* *}, p<0.001$ were obtained when the $\mathrm{GO}, \mathrm{RO}$ and BIS treated groups were compared to the LPS alone group. C. At $24 \mathrm{hr}$ following LPS $(1 \mu \mathrm{g} / \mathrm{ml})$ treatment in the absence or presence of PKC inhibitors, culture media from 24-well plates were collected for measurement of nitrite production by reactive microglia. ${ }^{* *}, p<0.01$ and ${ }^{* *}, p<0.001$ were obtained when the GO-, RO- and BIS-treated groups were compared to the LPS alone group. A representative experiment of four that were performed is shown. 


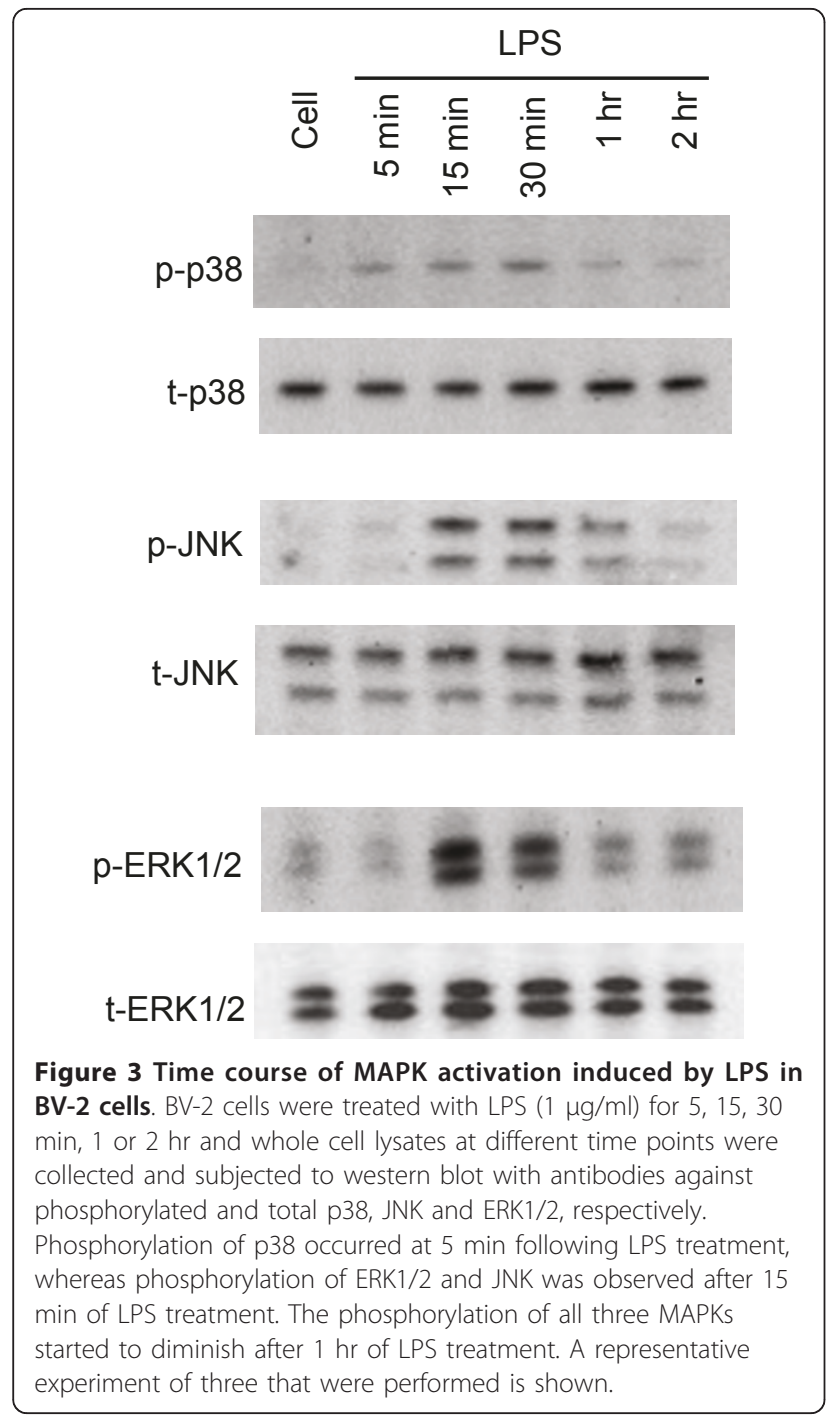

on the phosphorylation of p38 and JNK (Figure 4D). GO6976, a cPKC selective inhibitor, not only attenuates the phosphorylation of ERK $1 / 2$ by $83 \%$, but also suppresses the phosphorylation of p38 and JNK by $60 \%$ and $47 \%$, respectively (Figure 4D). The general PKC inhibitor, Bis-1, inhibits phosphorylation of ERK $1 / 2$ by $40 \%$ and JNK by $30 \%$. Taken together, these results suggest that although all of the MAPKs are involved in induction of iNOS in LPS-treated microglia, activation of specific PKC isoforms may lead to phosphorylation of distinct MAPKs.

\section{Activation of NF- $\kappa$ B contributes to PKC-mediated iNOS induction in reactive microglia}

$\mathrm{NF}-\kappa \mathrm{B}$ is one of the primary transcription factors that regulates iNOS expression. The regulation of iNOS mediated by ERK1/2 and p38 MAPK has been shown to require NF- $\kappa \mathrm{B}$ activation in rat glial cells $[34,36]$. In this study, we also investigated whether NF- $\kappa \mathrm{B}$ is involved in PKC-mediated iNOS production. CAY10470 is a recently developed NF- $\kappa \mathrm{B}$ inhibitor. It is synthesized from quinazoline derivative 6a, containing 4-phenoxyphenethyl moiety at the $\mathrm{C}(4)$-position with an $\mathrm{IC}_{50}$ of 11 $\mathrm{nM}$ to inhibit NF- $\kappa \mathrm{B}$ activation in human Jurkat cells [37]. CAY10470 significantly reduces iNOS production (Figure $5 \mathrm{~A}$ ), implying the involvement of NF- $\kappa \mathrm{B}$ activation in iNOS production induced by LPS in BV-2 cells. To further examine the interaction of PKC activation and NF- $\kappa \mathrm{B}$ during LPS treatment, we transfected BV-2 cells with an NF- $\kappa \mathrm{B}$-responsive luciferase construct containing an NF- $\kappa \mathrm{B}$ response element and luciferase. This construct encodes the firefly luciferase reporter gene under the control of a minimal CMV promoter and tandem repeats of the NF- $\kappa \mathrm{B}$ transcriptional response element (TRE). The NF- $\kappa \mathrm{B}$ reporter (Luc) can easily and rapidly monitor NF- $\kappa \mathrm{B}$ activity in the cells. Our data demonstrate that luciferase activity induced by LPS is significantly inhibited in the presence of the PKC inhibitors, rottlerin, GO6976 and Bis-1 (Figure 5B). Similarly, U0126 and SB203580 also significantly repress NF- $\kappa$ B activity (Figure $5 \mathrm{~B}$ ). Taken together, these results indicate that NF- $\kappa \mathrm{B}$ acts downstream of PKC and MAPKs to transcriptionally regulate iNOS production.

\section{The differential role of PKC isoforms in LPS-induced iNOS production and MAPK activation in BV-2 cells}

The above results suggest that LPS-induced iNOS production is mediated by PKC activation and MAPK phosphorylation. However, because of the lack of specificity and the potential non-target effects of the pharmacological inhibitors, it is still unclear whether specific PKC isoforms mediate microglial activation by LPS. To test this, we employed RNAi technologies to transfect BV-2 cells with isoform-specific siRNAs to suppress the expression of various PKC isoforms. To test for transfection efficiency, we used siGLO RISC-free siRNA as a positive control. siGLO RISC-free siRNA is a stable, fluorescent, and non-targeting control siRNA with RISC-free modification. Following $48 \mathrm{hr}$ of transfection, at least $90 \%$ of cells were transfected (Figure 6A). The transfection efficiency was further demonstrated by downregulation of various $\mathrm{PKC}$ isoforms (PKC $\alpha, \beta, \theta, \delta$, $\varepsilon$ and $\eta$ ) using PKC isoform-specific siRNAs by both conventional and quantitative real-time PCR analysis (Figures 6B and 6C). qRT-PCR data indicated that specific PKC siRNA downregulates relative PKC isoform mRNA level by 3-5 fold.

We then examined how downregulation of each specific PKC isoform could affect iNOS induction in BV-2 cells. At $48 \mathrm{hr}$ following PKC siRNA transfection, cells were treated with LPS for $6 \mathrm{hr}$ and iNOS expression was assessed by western blot (Figure 7A, B). Among the 


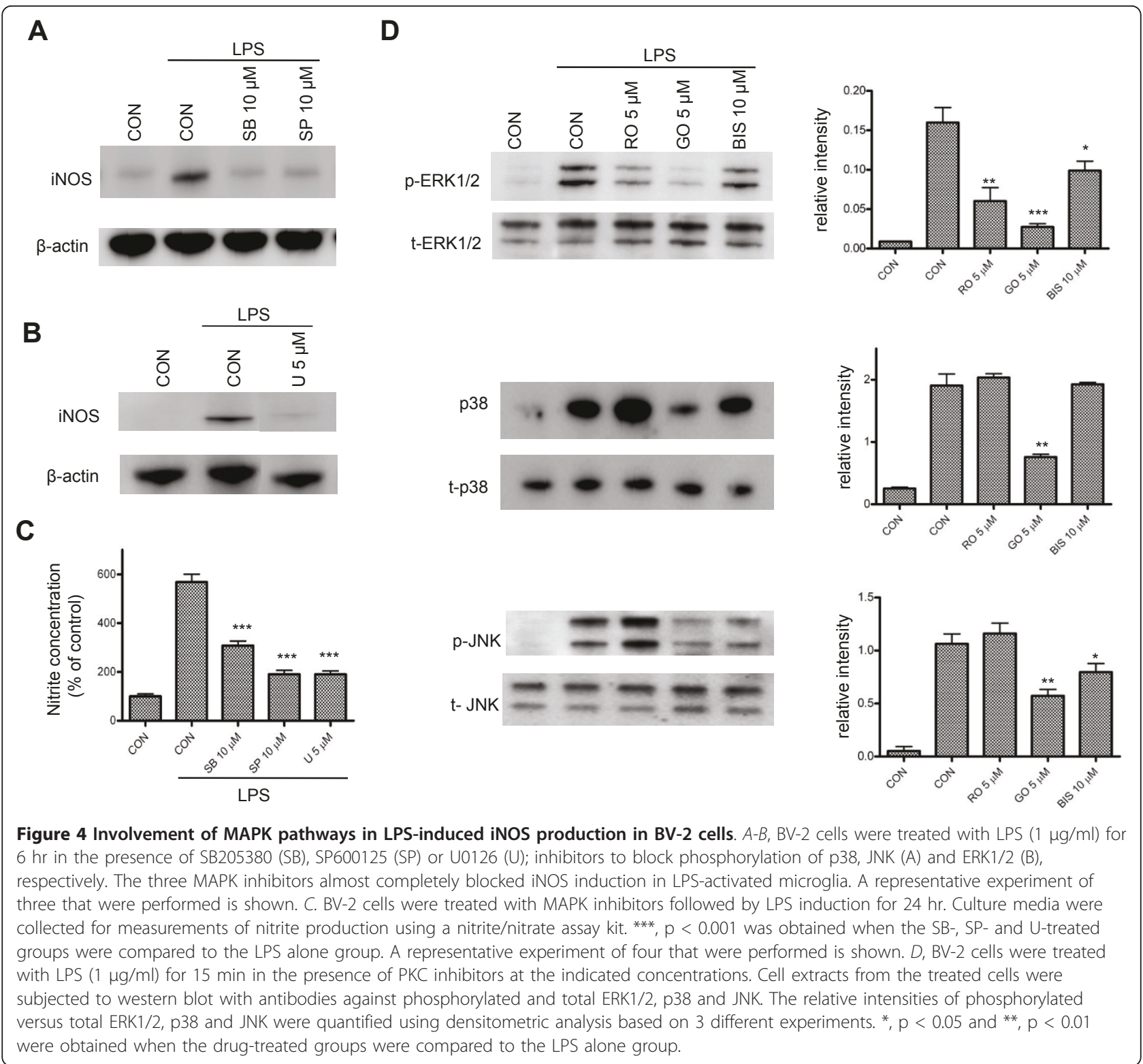

nPKC isoforms, knockdown of PKC $\delta$ appears to have the greatest inhibitory effect on iNOS expression, with a more-than-3-fold reduction observed. PKC $\eta$ and $\theta$ knockdown reduces iNOS by almost 2-fold, and knockdown of PKC $\varepsilon$ shows little effect (Figure 7A). Interestingly, downregulation of PKC $\beta$, but not PKC $\alpha$, significantly attenuates iNOS induction (Figure 7B), even though a very low mRNA expression of both cPKC isoforms is observed in BV-2 cells (Figure 1A, B). There is a 3 -fold reduction in iNOS expression in PKC $\beta$ siRNA-transfected cells when compared to RISC-free siRNA-transfected controls (Figure 7B). In summary, these data demonstrate that each PKC isoform has a different potency in triggering iNOS induction in LPS- activated microglia and that selective inhibition of PKC $\delta$ or $\beta$ may provide more focused anti-inflammatory effects.

To further identify the specific MAPK pathway through which PKC regulates the expression of iNOS, we examined the effect of PKC siRNAs on phosphorylation of various MAPKs. Similar to the results obtained using PKC inhibitors (Figure 4), downregulation of $n P K C s$ produces various degrees of inhibition of the phosphorylation of ERK1/2 (Figure 8A). Knockdown of PKC $\delta$ almost completely blocks ERK $1 / 2$ activation. PKC $\eta$ siRNA is shown to inhibit ERK1/2 phosphorylation by $60 \%$, but PKC $\varepsilon$ and $\theta$ siRNAs have no effect. Interestingly, PKC $\theta$ siRNA causes a $75 \%$ reduction of 


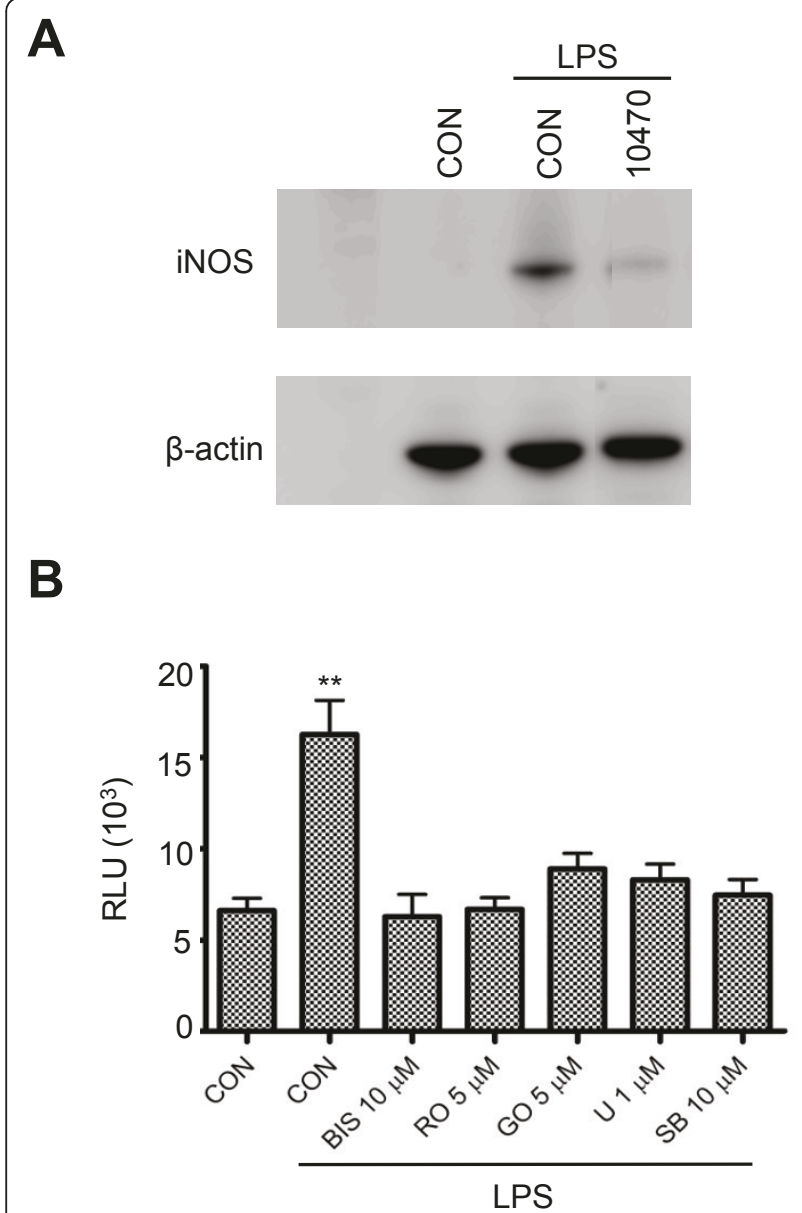

Figure 5 Involvement of the NF- $\kappa$ B pathway in LPS-activated BV-2 cells. A, BV-2 cells in 24-well plates were treated with LPS (1 $\mu \mathrm{g} / \mathrm{ml})$ for $6 \mathrm{hr}$ in the presence of CAY10470 (20 nM), an NF- $\kappa$ B inhibitor. Cell lysates were subjected to western blot analysis with antibodies against iNOS and $\beta$-actin. A representative experiment of three that were performed is shown. B, BV-2 cells in 96-well plates were transiently transfected with Luc-reporter gene with NF- $\kappa$ B promoter for $24 \mathrm{hr}$ and then treated with LPS $(1 \mu \mathrm{g} / \mathrm{ml})$ for $3 \mathrm{hr}$ in the presence of PKC or MAPK inhibitors. Luminescence from the cells was evaluated with a luciferase reporter assay system. RLUs (relative luminescence units) reflect the activity of NF- $\kappa \mathrm{B}$. U stands for U0126, and SB stands for SB203580. **, $p<0.01$ were obtained when the drug-treated groups were compared to the LPS alone group. A representative experiment of four that were performed is shown.

phosphorylation of p38 in LPS-treated microglia (Figure $8 \mathrm{~A})$, even though rottlerin doesn't exhibit any inhibitory effect (Figure 4C). Compared to the results obtained by using the cPKC inhibitor GO6976 (Figure 3C), we found that PKC $\beta$, but not PKC $\alpha$ siRNA, efficiently blocks phosphorylation of p38 by $65 \%$ based on densitometric analysis of the relative intensity of western blot bands (Figure $8 \mathrm{~B}$ ). However, both PKC $\alpha$ and $\beta$ siRNAs display nearly $50 \%$ inhibitory effects on ERK $1 / 2$ phosphorylation (Figure 8B). In addition, the isoform-specific PKC
siRNAs do not affect phosphorylation of JNK (Figure $8 \mathrm{~A}, \mathrm{~B})$, suggesting JNK activation is not involved in iNOS induction downstream of PKC activation. These results not only suggest that various $\mathrm{PKC}$ isoforms control diverse downstream MAPKs pathways to affect LPS-induced iNOS production in murine microglia, but also further demonstrate that the commonly used PKC inhibitors are less selective and that the use of individual PKC siRNAs should be more suitable for elucidating signaling pathways mediated by the various PKCs.

\section{Discussion}

Overproduction of NO by enhanced iNOS induction has been tightly linked to neuroinflammatory and neurodegenerative diseases [38-40]. A better understanding of the signaling mechanisms involved in the regulation of microglial iNOS has potential therapeutic implications. Previous studies mostly used PKC activators and inhibitors to determine the role of $\mathrm{PKC}$ in the regulation of iNOS production in murine microglia [26-30]. However, the absence of selectivity and the potential off-target effects of these pharmacological agents limit the ability to further define isoform-specific functions of the various PKCs. In the present study, we have employed PKC isoform-specific siRNAs to delineate novel molecular signaling pathways linking PKC to iNOS induction in BV-2 cells when exposed to LPS.

\section{Role of the PKC specific isoforms in LPS-induced iNOS production}

The PKC family consists of at least 10 serine/threonine protein kinases originally characterized by their dependency on lipids for catalytic activity $[41,42]$. The cPKCs require DAG and $\mathrm{Ca}^{2+}$, the nPKCs require DAG but not $\mathrm{Ca}^{2+}$, while the aPKCs require neither. The different modes of $\mathrm{PKC}$ regulation suggest that $\mathrm{PKC}$ isoforms may function differently in response to various stimuli. In BV-2 cells, pharmacological inhibition studies suggest that the nPKC and CPKC isoforms are integral to LPS-induced increases in iNOS expression and NO production (Figure 2), and isoform-specific siRNA knockdown confirms that PKC $\delta$ and PKC $\beta$ are the major $\mathrm{nPKC}$ and $\mathrm{cPKC}$ isoforms involved in the regulation of LPS-induced iNOS production in murine microglia (Figure 7).

A number of studies have reported that particular PKC isoforms are involved in the production of $\mathrm{NO}$ in several different cell types $[28,43-45]$. Here we demonstrate a principal role for PKC $\delta$ and PKC $\beta$ in the response to LPS exposure in murine BV-2 cells. These results are not only consistent with previous studies showing that PKC $\delta$ activation is required for regulating the production of iNOS in mouse peritoneal macrophages [27], human leukemia cells [46] and BV-2 cells 


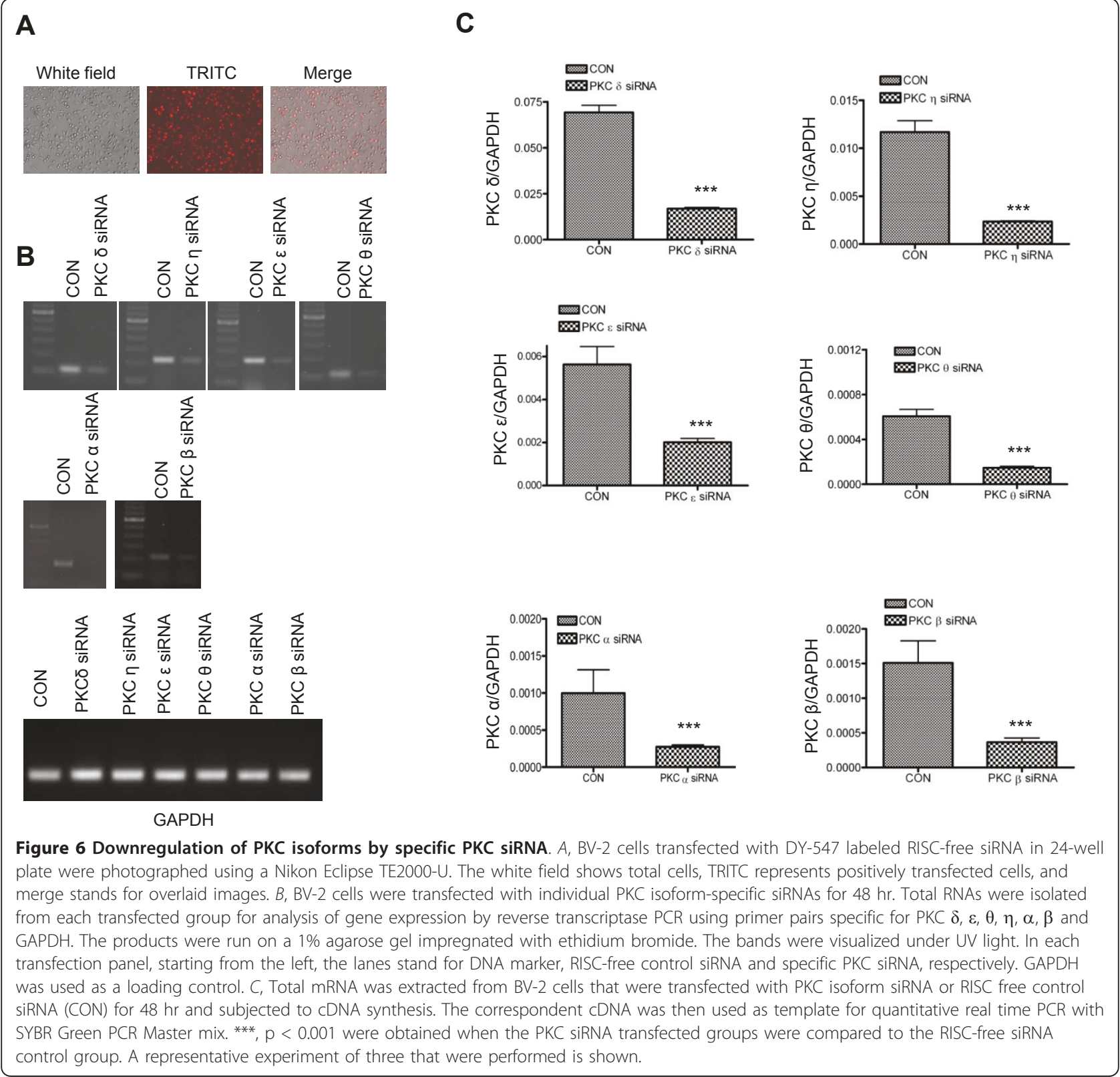

[29], but also for the first time suggest that PKC $\beta$ might play an important role in LPS-induced iNOS production in BV-2 cells even with its low levels of expression. It might be concluded that the primary role of PKC $\delta$ results from its high expression relative to other PKC isoforms (Figures $1 \mathrm{~A}$ and $1 \mathrm{~B}$ ). However, PKC $\beta$ expression is relatively low (Figure 1A) suggesting that induction of iNOS is dependent not only on levels of expression, but also on the activation of distinct PKC isoforms. Interestingly, PKC $\alpha$ and $\varepsilon$ have been shown to be the major PKC isoforms involved in the signaling pathways by which IFN $\gamma$ induces iNOS expression in the same cell line [28]. Collectively, these results suggest that distinct PKC isoforms are activated and implicated in the regulation of iNOS induction in a stimulus-specific manner.

\section{Downstream components of PKC activation in LPS- induced iNOS expression}

MAPKs. In the present study we also explored signaling pathways downstream of PKC that increase iNOS expression in response to LPS exposure. In general agreement with the observed effects of the three PKC inhibitors, rottlerin, GO6976, and Bis-1 (Figure 4D), knockdown of PKC $\delta, \eta, \alpha$ and $\beta$ expression reduces LPS-induced phosphorylation of ERK1/2 (Figures 8A 


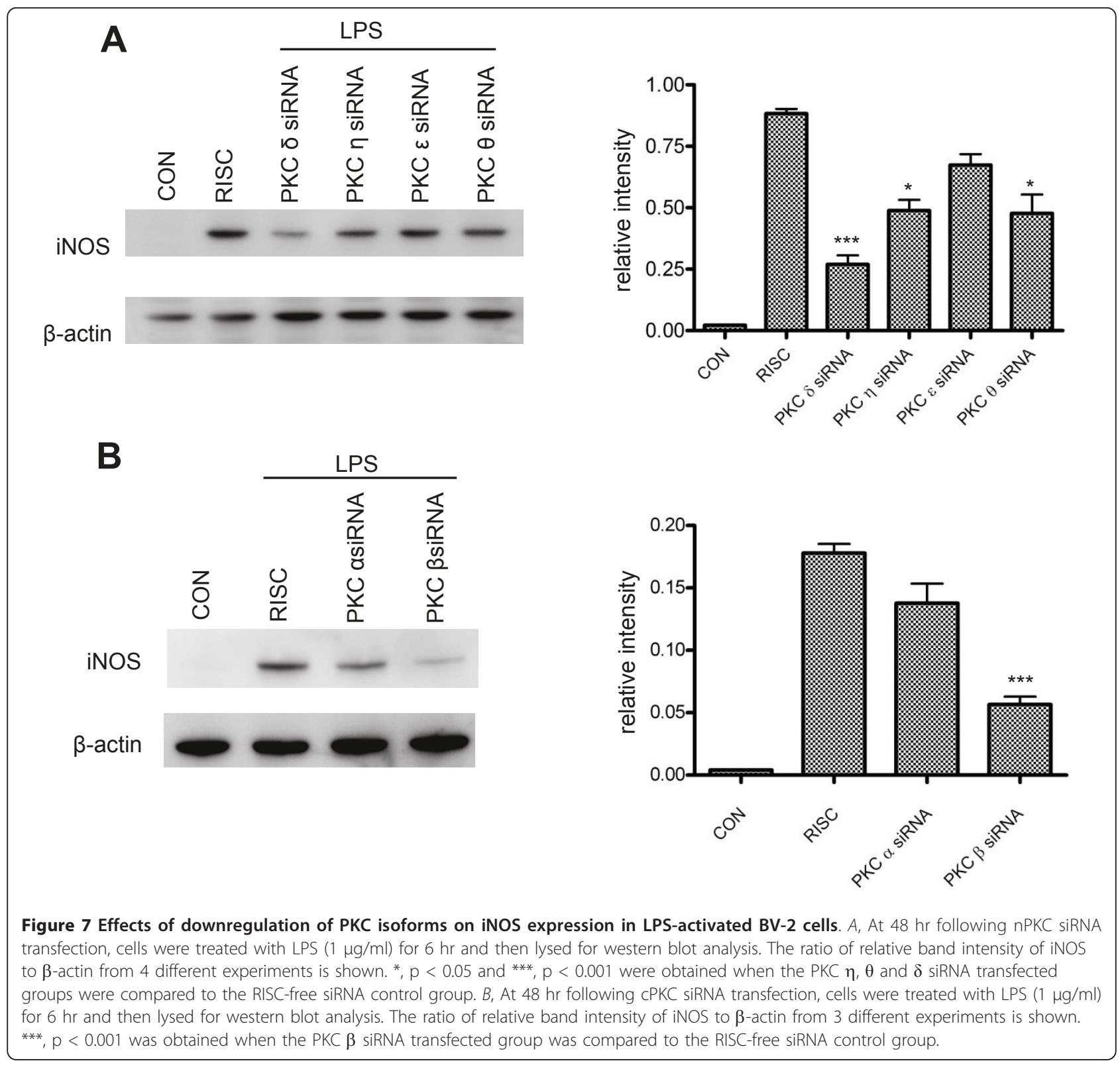

and $8 \mathrm{~B}$ ), whereas downregulation of PKC $\beta$ significantly inhibits LPS-induced phosphorylation of p38 (Figure $8 \mathrm{~B})$. No effect on phosphorylation of JNK is observed with individual cPKC or nPKC siRNA (Figures $8 \mathrm{~A}$ and $8 \mathrm{~B})$. Taken together, these results provide strong evidence that ERK1/2 and p38 are the main signaling pathways through which distinct $\mathrm{PKC}$ isoforms regulate iNOS induction in response to LPS. Moreover, these results suggest that distinct MAPKs are activated by specific PKC isoforms.

It has been shown that both p38 and ERK $1 / 2$ can mediate iNOS expression in glial cells [36]. However, the phosphorylation of ERK1/2 has been found to be involved in IFN $\gamma$-, but not in LPS-induced $\mathrm{NO}$ production, although NO production seems to be coupled to PKC $\delta$ activation under both stimulations [29]. The discrepancy between this report and our current study is unclear, but may be attributable to differences in the stage of BV-2 cells used in these studies. The same group has recently found that paraquat toxicity to microglia is mediated by PKC $\delta$ - and ERK1/2dependent ROS generation [47]. The fact that neither nPKCs nor cPKCs affect JNK phosphorylation (Figure 6) suggests that JNK is not involved in the signaling pathway of iNOS induction coupling to PKC activation. Interestingly, PKC $\theta$ siRNA significantly blocks p38 phosphorylation (Figure 8A), although the commonly used $\mathrm{nPKC}$ inhibitor rottlerin has no inhibitory effect 


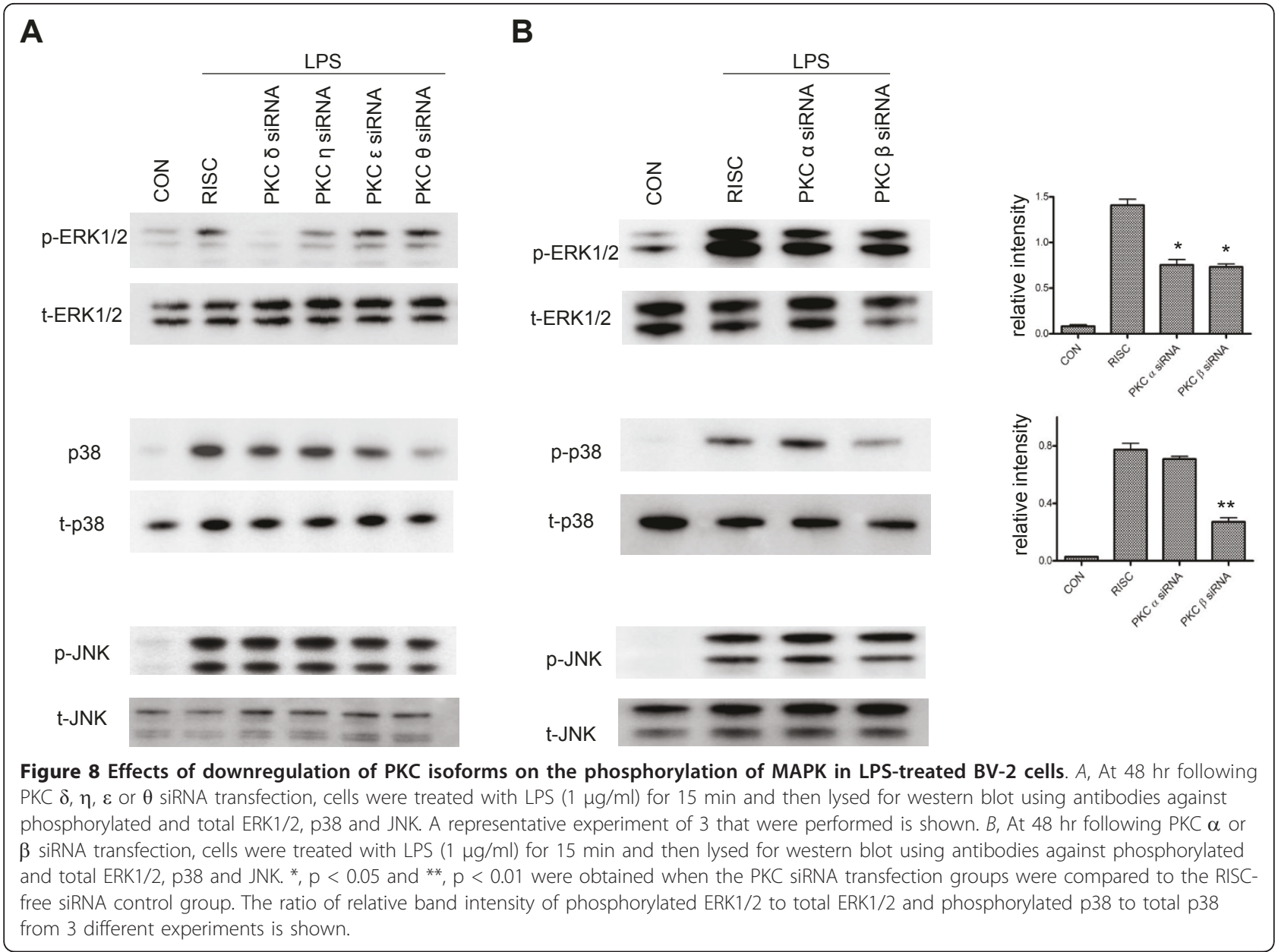

(Figure 4D). Similarly, GO6976 blocks JNK activation (Figure 4D) but the same phenomenon is not observed with the use of cPKC siRNAs (Figure 8B). These results further suggest that it might be misleading to draw conclusions on the role of specific PKC isoforms in the function of reactive microglia on the basis of pharmacological inhibition.

$N F-\kappa B$. It is known that iNOS expression is transcriptionally regulated. Activation of $\mathrm{p} 38$ has been shown to regulate NF- $\kappa \mathrm{B}, \mathrm{C} / \mathrm{EBP}$, and ATF-2 to induce iNOS expression in rat astroglia [48]. However, HIV-1 Tatinduced iNOS expression in human astrocytes is dependent on phosphorylation of ERK1/2 and transcriptional activation of C/EBP, but not NF- $\kappa$ B [49]. These studies indicate that different transcription factors can be recruited via one or more kinase pathways with respect to different inducers of iNOS. In this study, we find that activation of NF- $\kappa \mathrm{B}$ is required for iNOS induction through the application of CAY10470, an NF- $\kappa$ B-specific inhibitor (Figure 5). The observation that all of the PKC inhibitors - GO6976, rottlerin and Bis-1 - significantly block NF- $\kappa$ B activation strongly supports the conclusion that NF- $\kappa \mathrm{B}$ activation is required for iNOS induction in LPS-treated BV-2 cells.

\section{Conclusions}

By using pharmacological inhibitors and RNA interference, we have clearly demonstrated that LPS-induced iNOS expression and NO production in BV-2 is mediated by a signaling pathway involving the sequential activation of PKC, MAPK and NF- $\kappa \mathrm{B}$ as illustrated in Figure 9. In addition to elucidating the critical role of PKC $\delta$ in ERK1/2 phosphorylation and iNOS induction, our study reveals that PKC $\beta$ is also a principal PKC isoform triggering iNOS induction in reactive microglia, which is coupled through phosphorylation of $\mathrm{p} 38$. The partial inhibitory effects of PKC $\eta$ and $\theta$ on iNOS induction are due to their attenuation of the phosphorylation of ERK1/2 and p38, respectively. These data suggest that a novel interaction between the distinct PKC isoforms and the various MAPKs promotes iNOS induction. This interaction in different cell types may help to explain the discrepancy in the literature, and may also help guide the design of novel and selective PKC 


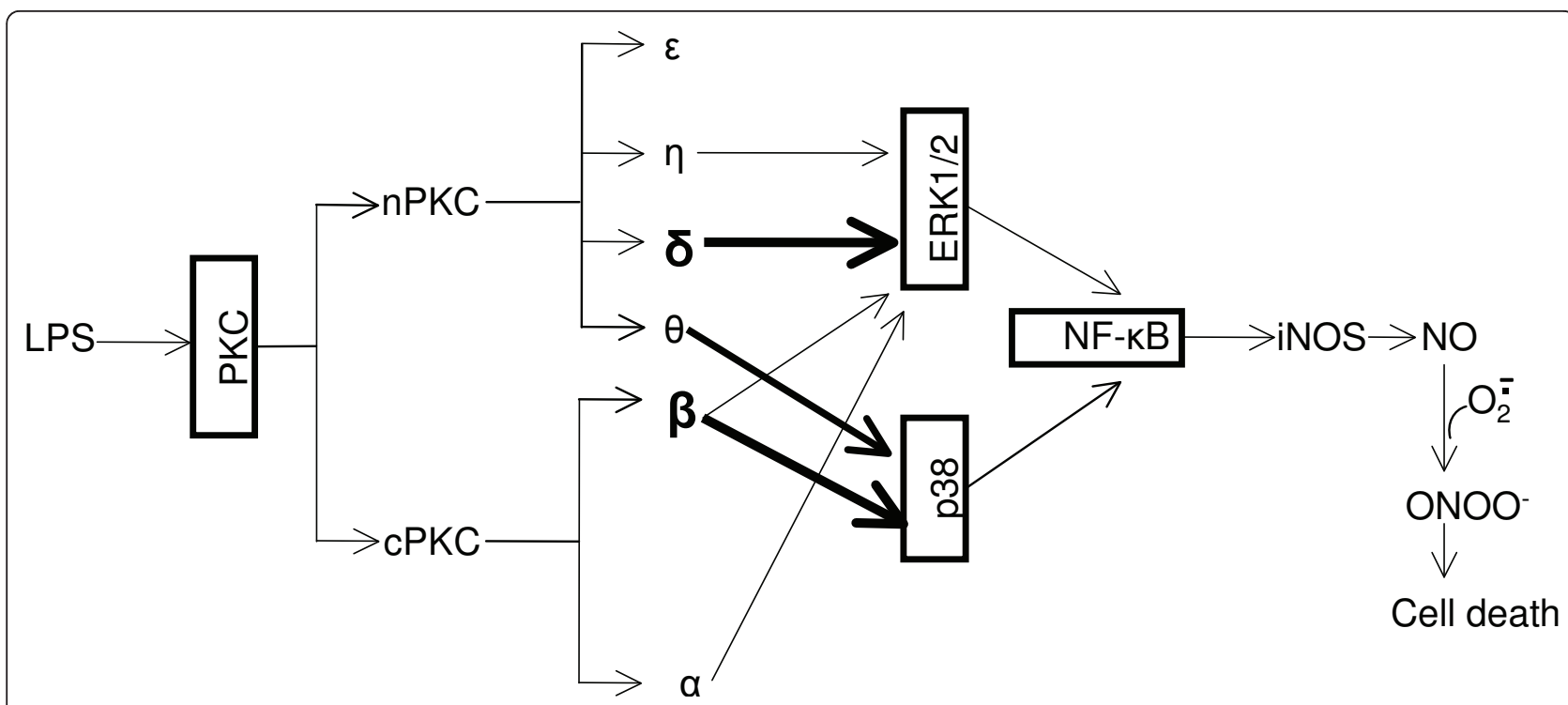

Figure 9 Novel pathway of PKC and MAPK-mediated transcriptional activation of iNOS in LPS-treated BV-2 cells. LPS activates CPKC and nPKC isoforms in BV-2 cells. Activation of PKC $\delta, \eta, \alpha$ and $\beta$ leads to ERK1/2 phosphorylation, whereas activation of PKC $\beta$ and $\theta$ mainly phosphorylates p38. Phosphorylation of ERK1/2 and p38 converges to the activation of NF- $\kappa$ B and results in upregulation of iNOS and production of NO. NO can then react with superoxide to form the potent oxidant, peroxynitrite, culminating in cell death. The heavy arrows indicate that PKC $\delta$ and $\beta$ are the two principal PKC isoforms involved in the signaling pathway proposed.

inhibitors for the treatment of many inflammatory and neurological diseases in which overproduction of nitric oxide plays a pathogenic role.

\section{Acknowledgements}

The authors wish to thank Dr. Thomas Flagg for his careful reading and critical comments and suggestions on the manuscript. This work was supported by grants from the Blast Lethality Injury and Research Program (R600-070-00000-00-106109), the National Multiple Sclerosis Society (RG3741) and start-up fund from the Uniformed Services University (R070 UX).

\section{Author details}

${ }^{1}$ Department of Anatomy, Physiology and Genetics, Uniformed Services University of the Health Sciences, 4301 Jones Bridge Road, Bethesda, MD 20814, USA. ${ }^{2}$ Program in Neuroscience, Uniformed Services University of the Health Sciences, 4301 Jones Bridge Road, Bethesda, MD 20814, USA.

\section{Authors' contributions}

JW designed and performed the experiments, analyzed the data and drafted the manuscript. RR performed some experiments and data analysis. YZ conceived of the study, participated in its design and coordination and helped to draft the manuscript. All authors read and approved the final version of the manuscript.

\section{Competing interests}

The authors declare that they have no competing interests.

Received: 24 October 2010 Accepted: 21 April 2011

Published: 21 April 2011

\section{References}

1. Banati RB, et al: Cytotoxicity of microglia. Glia 1993, 7(1):111-8.

2. Benveniste EN: Role of macrophages/microglia in multiple sclerosis and experimental allergic encephalomyelitis. J Mol Med 1997, 75(3):165-73.

3. Kim SU, de Vellis J: Microglia in health and disease. J Neurosci Res 2005, 81(3):302-13.
4. Ono K, Suzuki H, Sawada M: Delayed neural damage is induced by iNOSexpressing microglia in a brain injury model. Neurosci Lett 2010, 473(2):146-50.

5. Beckman JS, Koppenol WH: Nitric oxide, superoxide, and peroxynitrite: the good, the bad, and ugly. Am J Physiol 1996, 271(5 Pt 1):C1424-37.

6. Wilms $\mathrm{H}$, et al: Dimethylfumarate inhibits microglial and astrocytic inflammation by suppressing the synthesis of nitric oxide, IL-1beta, TNFalpha and IL-6 in an in-vitro model of brain inflammation. J Neuroinflammation 2010, 7:30.

7. Block ML, Zecca L, Hong JS: Microglia-mediated neurotoxicity: uncovering the molecular mechanisms. Nat Rev Neurosci 2007, 8(1):57-69.

8. Jaffrey SR, Snyder SH: Nitric oxide: a neural messenger. Annu Rev Cell Dev Biol 1995, 11:417-40.

9. Nathan C, Xie QW: Nitric oxide synthases: roles, tolls, and controls. Cell 1994, 78(6):915-8.

10. Bogdan C: Nitric oxide and the immune response. Nat Immunol 2001, 2(10):907-16

11. Popp R, Fleming I, Busse R: Pulsatile stretch in coronary arteries elicits release of endothelium-derived hyperpolarizing factor: a modulator of arterial compliance. Circ Res 1998, 82(6):696-703.

12. Ignarro $\sqcup$, et al: Nitric oxide as a signaling molecule in the vascular system: an overview. J Cardiovasc Pharmacol 1999, 34(6):879-86.

13. Nathan C: Inducible nitric oxide synthase: what difference does it make? J Clin Invest 1997, 100(10):2417-23.

14. Pahan $\mathrm{K}$, et al: Lovastatin and phenylacetate inhibit the induction of nitric oxide synthase and cytokines in rat primary astrocytes, microglia, and macrophages. J Clin Invest 1997, 100(11):2671-9.

15. Xie Z, et al: Peroxynitrite mediates neurotoxicity of amyloid betapeptide1-42- and lipopolysaccharide-activated microglia. J Neurosci 2002, 22(9):3484-92.

16. Li J, et al: Peroxynitrite generated by inducible nitric oxide synthase and NADPH oxidase mediates microglial toxicity to oligodendrocytes. Proc Natl Acad Sci USA 2005, 102(28):9936-41.

17. Bolli R, Dawn B, Xuan YT: Emerging role of the JAK-STAT pathway as a mechanism of protection against ischemia/reperfusion injury. J Mol Cell Cardiol 2001, 33(11):1893-6.

18. Janssen-Heininger YM, Macara I, Mossman BT: Cooperativity between oxidants and tumor necrosis factor in the activation of nuclear factor (NF)-kappaB: requirement of Ras/mitogen-activated protein kinases in 
the activation of NF-kappaB by oxidants. Am J Respir Cell Mol Biol 1999, 20(5):942-52.

19. Mattson MP, et al: Roles of nuclear factor kappaB in neuronal survival and plasticity. J Neurochem 2000, 74(2):443-56.

20. Saha RN, Pahan K: Regulation of inducible nitric oxide synthase gene in glial cells. Antioxid Redox Signal 2006, 8(5-6):929-47.

21. Nishizuka Y: The heterogeneity and differential expression of multiple species of the protein kinase C family. Biofactors 1988, 1(1):17-20.

22. Newton $A C$ : Regulation of the $A B C$ kinases by phosphorylation: protein kinase $C$ as a paradigm. Biochem J 2003, 370(Pt 2):361-71.

23. Dempsey $E C$, et al: Protein kinase $C$ isozymes and the regulation of diverse cell responses. Am J Physiol Lung Cell Mol Physiol 2000, 279(3): L429-38.

24. Wadsworth SJ, Goldfine H: Mobilization of protein kinase C in macrophages induced by Listeria monocytogenes affects its internalization and escape from the phagosome. Infect Immun 2002, 70(8):4650-60.

25. Nakai $\mathrm{M}$, et al: PKC and tyrosine kinase involvement in amyloid beta (2535)-induced chemotaxis of microglia. Neuroreport 1998, 9(15):3467-70.

26. Yoon $\mathrm{HJ}$, et al: Phorbol ester synergistically increases interferon-gammainduced nitric oxide synthesis in murine microglial cells. Neuroimmunomodulation 1994, 1(6):377-82.

27. Bhatt $\mathrm{KH}$, et al: Protein kinase Cdelta and protein tyrosine kinase regulate peptidoglycan-induced nuclear factor-kappaB activation and inducible nitric oxide synthase expression in mouse peritoneal macrophages in vitro. Mol Immunol 2010, 47(4):861-70.

28. Kang $\mathrm{J}$, et al: Identification of protein kinase $\mathrm{C}$ isoforms involved in interferon-gamma-induced expression of inducible nitric oxide synthase in murine BV2 microglia. Neurosci Lett 2001, 299(3):205-8.

29. Shen $\mathrm{S}$, et al: Distinct signaling pathways for induction of type II NOS by IFNgamma and LPS in BV-2 microglial cells. Neurochem Int 2005, 47(4):298-307.

30. Han $\mid \mathrm{O}$, et al: Synergistic expression of inducible nitric oxide synthase by phorbol ester and interferon-gamma is mediated through NF-kappaB and ERK in microglial cells. J Neurosci Res 2003, 73(5):659-69.

31. Kang J, et al: Reactive oxygen species mediate A beta(25-35)-induced activation of BV-2 microglia. Neuroreport 2001, 12(7):1449-52.

32. Goekjian PG, Jirousek MR: Protein kinase $C$ in the treatment of disease: signal transduction pathways, inhibitors, and agents in development. Curr Med Chem 1999, 6(9):877-903.

33. Gschwendt M, et al: Rottlerin, a novel protein kinase inhibitor. Biochem Biophys Res Commun 1994, 199(1):93-8.

34. Fiebich BL, et al: Inhibition of LPS-induced p42/44 MAP kinase activation and iNOS/NO synthesis by parthenolide in rat primary microglial cells. J Neuroimmunol 2002, 132(1-2):18-24.

35. Tanel A, Averill-Bates DA: P38 and ERK mitogen-activated protein kinases mediate acrolein-induced apoptosis in Chinese hamster ovary cells. Cell Signal 2007, 19(5):968-77.

36. Bhat NR, et al: Extracellular signal-regulated kinase and $p 38$ subgroups of mitogen-activated protein kinases regulate inducible nitric oxide synthase and tumor necrosis factor-alpha gene expression in endotoxinstimulated primary glial cultures. J Neurosci 1998, 18(5):1633-41.

37. Tobe $M$, et al: A novel structural class of potent inhibitors of NF-kappa B activation: structure-activity relationships and biological effects of 6aminoquinazoline derivatives. Bioorg Med Chem 2003, 11(18):3869-78.

38. Wada $\mathrm{K}$, et al: Role of nitric oxide in traumatic brain injury in the rat. $J$ Neurosurg 1998, 89(5):807-18.

39. Endoh M, Maiese $K$, Wagner J: Expression of the inducible form of nitric oxide synthase by reactive astrocytes after transient global ischemia. Brain Res 1994, 651(1-2):92-100.

40. Satake $K$, et al: Nitric oxide via macrophage iNOS induces apoptosis following traumatic spinal cord injury. Brain Res Mol Brain Res 2000, 85(12):114-22.

41. Newton AC: Protein kinase C: structural and spatial regulation by phosphorylation, cofactors, and macromolecular interactions. Chem Rev 2001, 101(8):2353-64

42. Takai $Y$, et al: Studies on a cyclic nucleotide-independent protein kinase and its proenzyme in mammalian tissues. I Purification and characterization of an active enzyme from bovine cerebellum. J Biol Chem 1977, 252(21):7603-9.
43. Ginnan R, et al: PKC-delta mediates activation of ERK1/2 and induction of iNOS by IL-1 beta in vascular smooth muscle cells. Am J Physiol Cell Physiol 2006, 290(6):C1583-91.

44. Pham TN, et al: Protein kinase C-eta (PKC-eta) is required for the development of inducible nitric oxide synthase (iNOS) positive phenotype in human monocytic cells. Nitric Oxide 2003, 9(3):123-34.

45. Nagareddy PR, et al: Selective inhibition of protein kinase $\mathrm{C}$ beta(2) attenuates inducible nitric oxide synthase-mediated cardiovascular abnormalities in streptozotocin-induced diabetic rats. Diabetes 2009 58(10):2355-64.

46. Deb DK, et al: Activation of protein kinase C delta by IFN-gamma. J Immunol 2003, 171(1):267-73.

47. Miller RL, Sun GY, Sun AY: Cytotoxicity of paraquat in microglial cells: Involvement of PKCdelta- and ERK1/2-dependent NADPH oxidase. Brain Res 2007, 1167:129-39.

48. Bhat NR, et al: p38 MAPK-mediated transcriptional activation of inducible nitric-oxide synthase in glial cells. Roles of nuclear factors, nuclear factor kappa B, CAMP response element-binding protein, CCAAT/enhancerbinding protein-beta, and activating transcription factor-2. J Biol Chem 2002, 277(33):29584-92.

49. Liu X, et al: Human immunodeficiency virus type 1 (HIV-1) tat induces nitric-oxide synthase in human astroglia. J Biol Chem 2002, 277(42):39312-9.

doi:10.1186/1742-2094-8-38

Cite this article as: Wen et al: Specific PKC isoforms regulate LPSstimulated iNOS induction in murine microglial cells. Journal of Neuroinflammation 2011 8:38.

\section{Submit your next manuscript to BioMed Central and take full advantage of:}

- Convenient online submission

- Thorough peer review

- No space constraints or color figure charges

- Immediate publication on acceptance

- Inclusion in PubMed, CAS, Scopus and Google Scholar

- Research which is freely available for redistribution

Submit your manuscript at www.biomedcentral.com/submit
Ciomed Central 